MENDONÇA, F.V.S.; MENEZES, J.B.; GUIMARÃES, A.A.; SOUZA, P.A.; SIMÕES, A.N.; SOUZA, G.L.F.M. Armazenamento do melão amarelo, híbrido RX20094, sob temperatura ambiente. Horticultura Brasileira, Brasília, v.22, n.1 p. 76-79, jan-mar 2004.

\title{
Armazenamento de melão amarelo, híbrido RX 20094, sob temperatura ambiente
}

\author{
Fábio Vinícius de S. Mendonça ${ }^{1}$; Josivan B. Menezes; Adriana A. Guimarães²; Pahlevi A. De Souza ${ }^{3}$; \\ Adriano do N. Simões ${ }^{1}$; Georgiana L.F.M. Souza ${ }^{2}$ \\ ESAM, NEP, C. Postal 137, 59625-900 Mossoró-RN; E-mail: fabiovsm45@hotmail.com; 'Estudante mestrado em Fisiol. Vegetal, UFV, \\ 36570-000 Viçosa-MG; ${ }^{2}$ Estudante mestrado em Tecnol. Alimentos, UFV; ${ }^{3}$ Estudante doutorado em Fitotecnia, UFV
}

\section{RESUMO}

A vida útil pós-colheita do melão amarelo híbrido RX 20094 foi avaliada, estudando-se características visuais, físicas e físico-químicas dos frutos em pós-colheita em ensaio conduzido no laboratório da Escola Superior de Agricultura de Mossoró. Utilizou-se delineamento inteiramente casualizado com seis tratamentos, referentes aos períodos de armazenamento $(0 ; 5 ; 10 ; 15 ; 20 ;$ e 25 dias $)$ e 5 repetições, com dois frutos por parcela. Os frutos foram mantidos à temperatura de $30 \pm 1^{\circ} \mathrm{C}$ e UR de $50 \pm 5 \%$. Foram feitas avaliações em intervalos de 5 dias, avaliando-se a firmeza da polpa, perda de massa, aparências externa e interna e conteúdo de sólidos solúveis (SS). Observou-se efeito do tempo de armazenamento para todas as características avaliadas. A firmeza da polpa e as aparências externa e interna foram os principais fatores responsáveis pela perda de qualidade do melão. A vida útil do híbrido RX-20094 foi estimada em até no mínimo 25 dias de armazenamento sob temperatura ambiente.

Palavras-chave: Cucumis melo L., pós-colheita, qualidade, armazenamento.

\begin{abstract}
Yellow melon, RX 20094 hybrid, stored at room temperature

The postharvest shelflife of yellow melon RX20094 hybrid was obtained through visual, physical, and physical-chemical evaluations in two experiments carried out at Escola Superior de Agricultura de Mossoró, Rio Grande do Norte State, Brasil. A completely randomized design with six treatments, consisting of storage days $(0 ; 5 ; 10 ; 15 ; 20 ;$ and 25$)$ and five replications, with 2 fruits per plot, was utilized. The fruits were kept at the temperature of $30 \pm 1^{\circ} \mathrm{C}$ and $50 \pm 5 \%$ of relative humidity. Evaluations were made at five-day intervals with the determination of flesh firmness, weight loss, external and internal appearances and soluble solids content (SS). The storage days had effect on all characteristics. Yellow melons RX20094 hybrid maintained good quality characteristics for up to a storage period of 25 days at room temperature.
\end{abstract}

Keywords: Cucumis melo L., postharvest, quality, shelf life.

(Recebido para publicação em 17 de dezembro de 2002 e aceito em 02 de novembro de 2003)

$\mathrm{O}$ Agropolo Mossoró-Assu é respon sável pela maior concentração de empreendimentos com frutos tropicais, onde o melão assume uma proporção privilegiada. As regiões do Baixo Assu e Chapada do Apodi no RN, e Baixo Jaguaribe no CE, são responsáveis pelas maiores áreas produtoras de melão no Semi-Árido do Nordeste (Dias et al.,1998). O RN vem se destacando nos últimos anos como principal Estado produtor e exportador de melão do Brasil, por possuir condições edafoclimáticas que favorecem a cultura do meloeiro, como por exemplo, a alta luminosidade, os baixos índices pluviométricos, com exceção do período de janeiro a maio, e a baixa umidade relativa do ar, permitem uma produção durante quase todo o ano.

Apesar das grandes empresas produtoras de melão do Agropolo MossoróAssu dominarem tecnologia necessária à obtenção de um "produto" de boa qualidade, como, por exemplo, utilização de câmaras frias, existem ainda na região pequenos produtores que não têm condições de adotar uma estrutura de cadeia de frio. Assim, são obrigados a armazenar seus frutos em condições ambientes por períodos relativamente prolongados até a comercialização. Por isso, as variedades preferencialmente cultivadas do grupo inodorus, representado pelo melão "amarelo" com excelente conservação pós-colheita (Cocozza, 1997), comparado às cultivares dos grupos reticulatus e cantaloupe (Souza et al., 1994), que não alcançam 14 dias de vida útil pós-colheita sob temperatura ambiente.

Diversos genótipos estão sendo cultivados no RN, dentre eles, o 'Gold Mine', 'AF-646', e 'Piel del Sapo', todos pertencentes ao grupo inodorus. A cada ano verifica-se a introdução de novos genótipos (comumente referidos como híbridos) com o objetivo de diversificar e melhorar a qualidade do produto a ser oferecido aos mercados interno e externo., Porém, o conhecimento do comportamento pós-colheita desses novos materiais ainda é muito limi- tado (Morais,1998). Para melão o termo qualidade tem sido relacionado com diferentes características como conteúdo de sólidos solúveis, firmeza da polpa, perda de massa e aparências externa e interna (Menezes et al., 2001), indicando a aceitabilidade direta do produto pelo consumidor final. Os teores de açúcares em frutos, normalmente, constituem 65 a $85 \%$ do conteúdo de sólidos solúveis (Chitarra e Chitarra, 1990). Portanto é de fundamental importância conhecer o comportamento pós-colheita de novos híbridos para sua introdução em plantios comerciais, tendo em vista que os principais mercados consumidores (Região Sudeste do Brasil e a comunidade Européia) necessitam produto com bom potencial de conservação pós-colheita além de características de qualidade e vida de prateleira (Gonçalves et al.,1996; Brasil et al.,1998). O presente trabalho objetivou avaliar a qualidade e a vida útil pós-colheita do melão amarelo, híbrido RX20094 sob temperatura ambiente. 


\section{MATERIAL E MÉTODOS}

Os frutos foram obtidos de plantio comercial localizado no Agropólo Mossoró-Assu, produzidos de acordo com as práticas culturais usuais na região, utilizando-se sistema de irrigação localizada, em LATOSSOLO VERMELHO-AMARELO. O clima é quente e seco, com precipitação pluviométrica anual de $423 \mathrm{~mm}$, temperatura média mensal máxima e mínima de 33 e $29^{\circ} \mathrm{C}$, respectivamente. $\mathrm{O}$ peso médio dos frutos variou de 1,5 a $1,8 \mathrm{~kg}$, o que permite a classificação como tipo 6 (6 frutos por caixa), colhidos no estádio de maturação comercial. Após a colheita, os frutos foram conduzidos ao Laboratório de Pós-colheita da ESAM, onde foram pesados, selecionados (eliminando-se os frutos portadores de imperfeições) e armazenados num intervalo de temperatura de $30 \pm 1^{\circ} \mathrm{C}$ e umidade relativa de $50 \pm 5 \%$ por até 25 dias. As avaliações foram feitas em intervalos regulares de cinco dias. A perda de massa foi calculada em relação à massa inicial dos frutos no dia da colheita e aquela obtida, em cada intervalo de armazenamento, sendo os resultados expressos em percentagem (\%). As avaliações de aparência externa (depressões, murcha ou lesões fúngicas) e aparência interna (colapso interno, sementes soltas ou presença de líquido) foram feitas, utilizando-se uma escala visual e subjetiva, segundo a classificação utilizada por Gomes Júnior, et al. (2000), considerandose a ausência ou presença de defeitos ( $1=$ fruto que se apresenta extremamente marcado pelos defeitos destacados; $2=$ severo; 3= médio; 4= leve; 5= ausência dos defeitos). Quando a nota obtida foi $£ 3,0$ o fruto foi considerado indesejável para o consumo. Para a avaliação da firmeza da polpa, o fruto foi dividido longitudinalmente, sendo que, em cada uma das metades procedeu-se duas leituras (em regiões opostas) com penetrômetro de marca McCormick modelo FT 327 com plunger de $8 \mathrm{~mm}$ de diâmetro, sendo os resultados obtidos em libras (lbf) e transformados para newton $(\mathrm{N})$ utilizando-se o fator de conversão 4,45. O conteúdo de sólidos solúveis (SS) foi determinado por refratometria, utilizando-se um refratômetro digital modelo PR

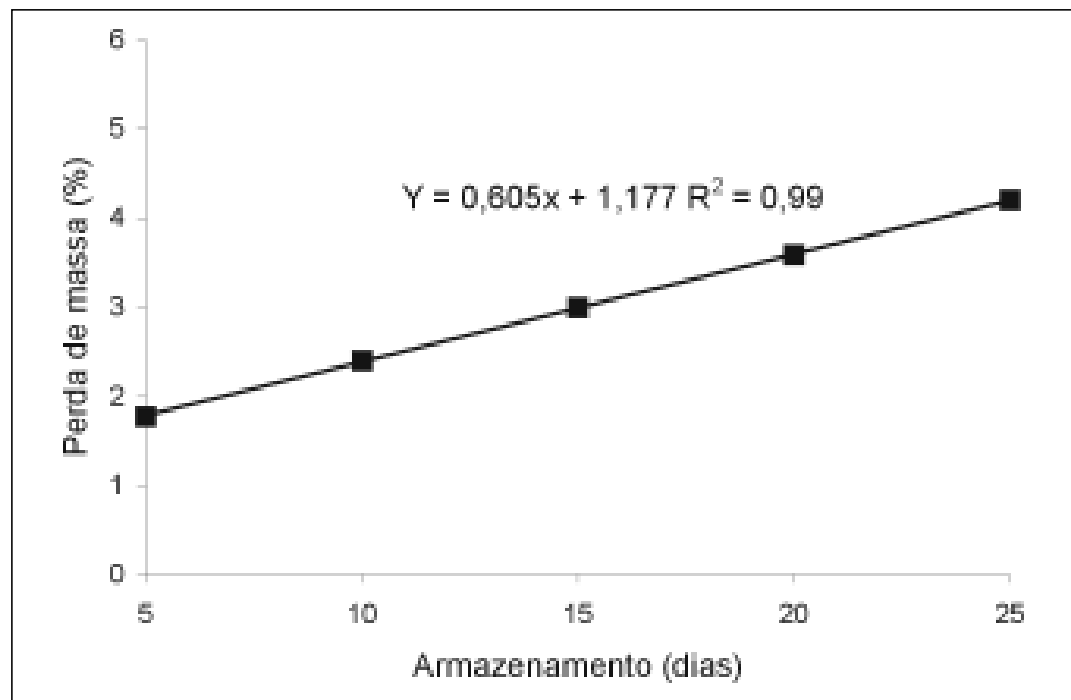

Figura 1. Perda de massa de melão amarelo, genótipo RX-20094, armazenados a temperatura ambiente $\left(30^{\circ} \mathrm{C} \pm 1^{\circ} \mathrm{C}\right.$ e UR de $\left.50 \pm 5 \%\right)$. Mossoró, ESAM, 2000 .

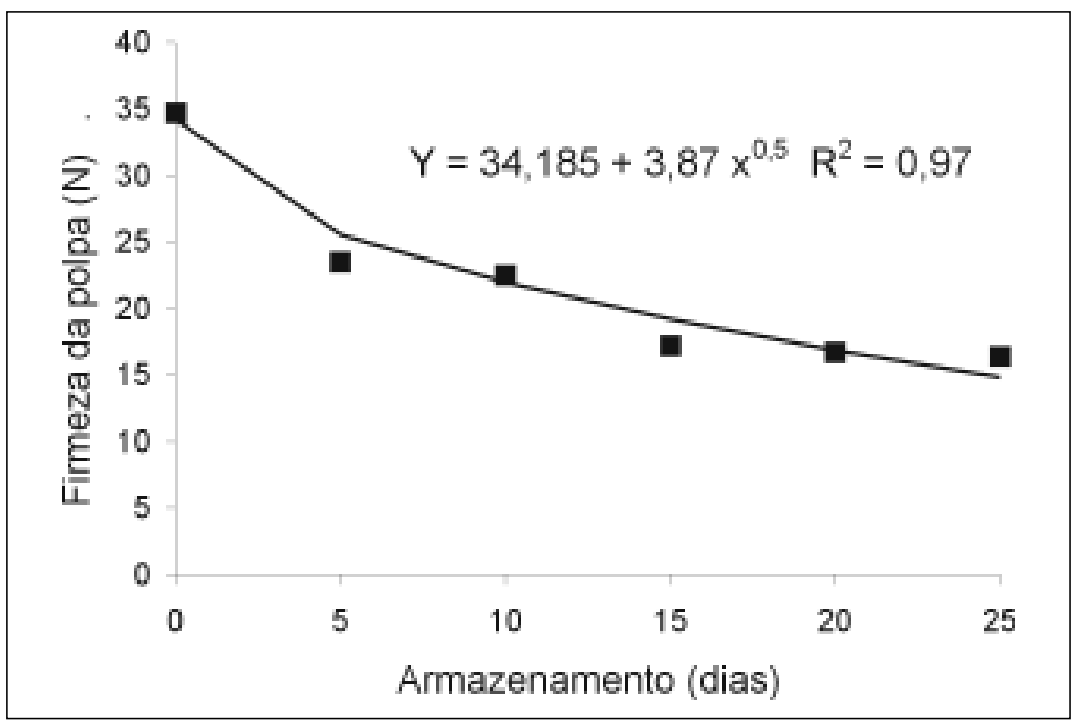

Figura 2. Firmeza de polpa de melão amarelo, genótipo RX-20094, armazenados a temperatura ambiente $\left(30^{\circ} \mathrm{C} \pm 1^{\circ} \mathrm{C}\right.$ e UR de $\left.50 \pm 5 \%\right)$. Mossoró, ESAM, 2000.

-100 Palette, com correção automática de temperatura e os resultados expressos em percentagem, conforme metodologia proposta por Kramer (1973).

$\mathrm{O}$ experimento foi conduzido em delineamento inteiramente casualizado com seis tratamentos, referentes a períodos de armazenamento $(0 ; 5 ; 10 ; 15 ; 20$; e 25 dias), e cinco repetições. Cada parcela foi composta por 2 frutos, totalizando 60 frutos no experimento. Os resultados foram submetidos à análise de variância através do software SPSSPC (Norusis, 1990) e, detectado efeito significativo, procedeu-se à regressão polinomial através do software Table Curve (Jandel Scientific, 1991).

\section{RESULTADOS E DISCUSSÃO}

Para todas as variáveis analisadas houve efeito significativo do híbrido RX 20094 em relação ao tempo de armazenamento.

A modificação na perda de massa dos frutos estudados foi caracterizada por um acréscimo ao longo do armazenamento variando de $1,7 \%$ no início para $4,2 \%$ ao 


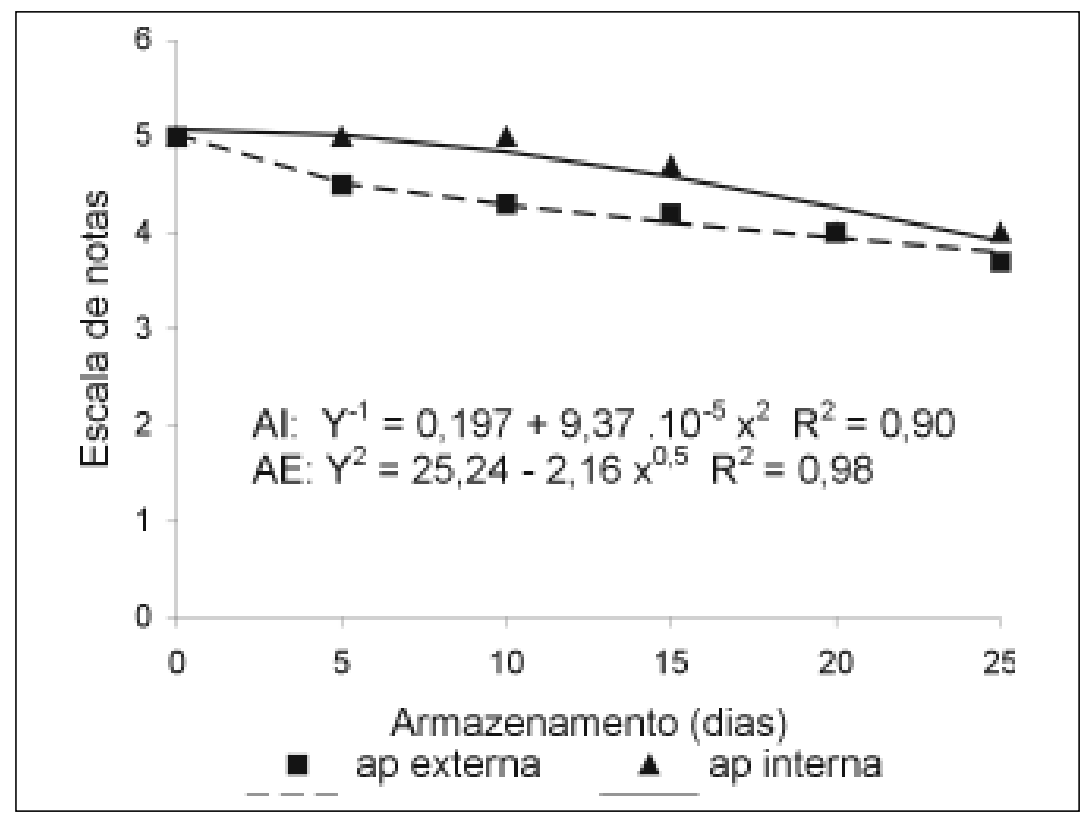

Figura 3. Avaliação subjetiva da aparência interna (AI) e externa (AE) de melão amarelo, genótipo RX-20094, armazenados a temperatura ambiente $\left(30^{\circ} \mathrm{C} \pm 1^{\circ} \mathrm{C}\right.$ e UR de $\left.50 \pm 5 \%\right)$. Mossoró, ESAM, 2000.

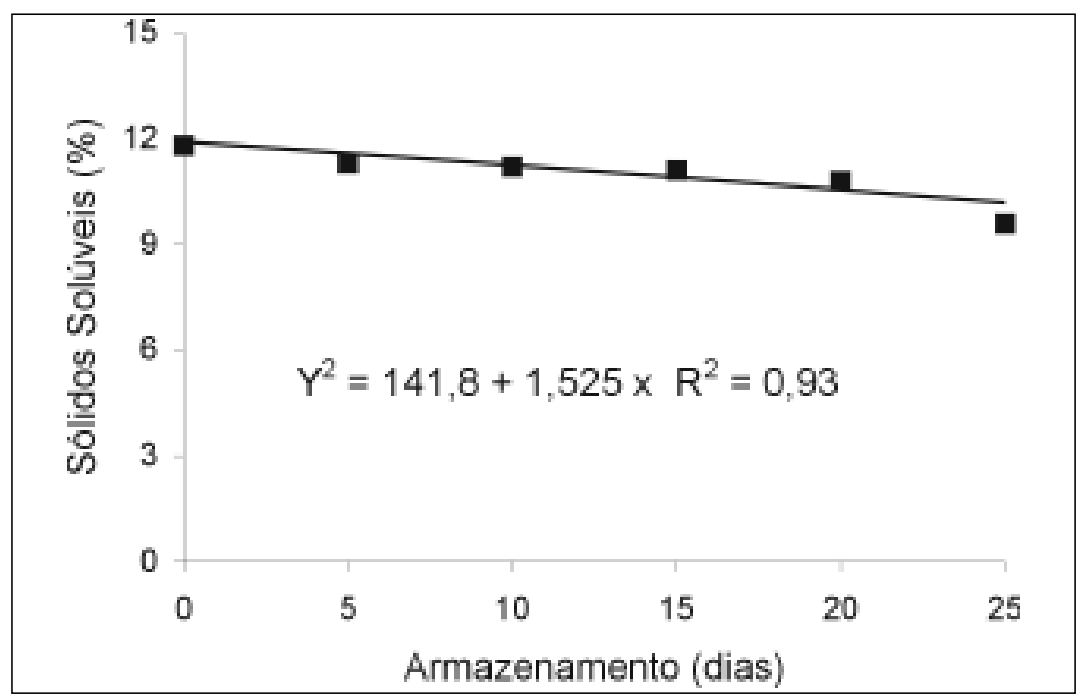

Figura 4. Conteúdo de sólidos solúveis de melão amarelo, genótipo RX-20094, armazenados a temperatura ambiente $\left(30^{\circ} \mathrm{C} \pm 1^{\circ} \mathrm{C}\right.$ e UR de $\left.50 \pm 5 \%\right)$. Mossoró, ESAM, 2000.

final do experimento (Figura 1). A perda de massa pode ser atribuída, principalmente, à perda de umidade e de material de reserva, pela transpiração e respiração respectivamente, sendo um dos principais fatores limitantes da vida útil póscolheita de melões, sofrendo influencia de inúmeros fatores, como os da cultivar, dos tratamentos pós-colheita, das condições e duração do armazenamento entre outros (Mayberry e Hartz, 1992;
Menezes, 1996). A perda de umidade pode ser uma das principais causas de perda quantitativa, mas também provoca perdas qualitativas ocasionando murchamento do fruto (Menezes, 1996). Gomes Júnior (2000), trabalhando com duas cultivares de melão da variedade Inodorus (AF 646 e Rochedo) em quatro temperaturas de armazenagem $\left(6^{\circ} \mathrm{C}\right.$; $\left.8^{\circ} \mathrm{C} ; 10^{\circ} \mathrm{C} ; 12^{\circ} \mathrm{C}\right)$ verificou aos 35 dias deterioração, pois resulta não apenas em de armazenamento uma variação de 2,37 a 2,94\% para 'AF 646' e 0,94 a 2,04\% para 'Rochedo'.

A firmeza de polpa decresceu durante o armazenamento, com uma média no inicio do experimento ( $0 \mathrm{dia}$ ) de 34 $\mathrm{N}$ e ao final (25 dias) de $17 \mathrm{~N}$ (Figura 2 ), verificando-se uma perda de firmeza de $52 \%$ durante o tempo transcorrido. Menezes et al. (1995) estudaram a caracterização pós-colheita do melão amarelo 'Agroflora 646', e verificaram valores iniciais de firmeza de polpa variando de $83,63 \mathrm{~N}$ ao início e 33,07 $\mathrm{N}$ ao final, com uma redução em torno de $60 \%$. O amolecimento da polpa do melão pode estar relacionado ao aumento da atividade de hidrolases tais como a poligalacturonase $(\mathrm{PG}) \quad \mathrm{e}$ pectinametilesterase (PME) durante o armazenamento do fruto (Menezes et al., 1995). Gomes Júnior (2000), trabalhando com melões amarelos, do grupo inodorus, genótipos 'AF 646' e 'Rochedo' sob armazenamento refrigerado, também verificou redução gradativa nos valores de firmeza de polpa. A firmeza da polpa é uma característica que varia com a variedade. Para melões do grupo inodorus existem grandes diferenças da firmeza da polpa no momento da colheita. Segundo Filgueiras et al. (2000) as cultivares AF 646, TSX 32046 e Gold Mine apresentam por ocasião da colheita 24,35 e $40 \mathrm{~N}$ respectivamente.

Observou-se decréscimo para as aparências externa e interna durante o período de armazenamento (Figura 3). A aceitabilidade dos frutos no mercado interno e externo é determinada, principalmente, pela sua qualidade visual. Frutos com nota inferior a 3 são indesejáveis para o consumo. O melão $\mathrm{RX}$ 20094, apresentou aos 25 dias, nota 3,7 para a aparência externa e 4,0 para a interna, possibilitando sua comercialização (Figura 3). Resultados semelhantes foram obtidos com o melão 'Agroflora 646' no agropolo Mossoró-Assu, que apresentou nota superior a 3 tanto externa como internamente aos 25 dias de armazenamento a $25 \pm 2^{\circ} \mathrm{C}$ (Menezes et al.,1995). Já o melão amarelo 'Yellow King' teve vida útil pós-colheita de 45 dias, sendo que, até os 40 dias estava com aparência superior a três, com boas condi- 
ções de comercialização (Carvalho et al., 1995).

Observou-se decréscimo gradual para os valores de sólidos solúveis ao longo do tempo de armazenamento (Figura 4), porém esses valores foram superiores a $9 \%$, para os 25 dias de armazenamento, considerados ideais para a comercialização no mercado externo (Gayet, 1994). Ao contrario de frutos climatéricos como banana e maçã, que armazenam apreciáveis quantidades de amido para a conversão em açúcares durante o armazenamento (Brady e Young, 1987), o tecido mesocárpico do melão não contém essa reserva. $\mathrm{O}$ teor de açucares, que compõe $\pm 90 \%$ dos SS, é determinado pelo tempo que o fruto fica preso à planta (Kroen et al., 1991), não aumentando após a colheita. Carvalho et al. (1995) verificaram, que os teores de sólidos solúveis não variaram significativamente, em melão amarelo 'Yellow King', armazenado a temperatura ambiente. No entanto, Menezes et al. (1995), verificaram decréscimo de 10,07 (0 dia) a 8,10\% (49 dias) em melão ' $\mathrm{AF}-646^{\prime}$ ' à temperatura de $\pm 25^{\circ} \mathrm{C}$.

Com base nos resultados apresentados neste trabalho e considerando que a firmeza da polpa e as aparências externa e interna são o principal fator responsável pela perda na qualidade em melão, pode-se concluir que a vida útil pós-colheita do híbrido RX 20094 foi estimada em até no mínimo 25 dias de armazenamento sob condições ambiente, em virtude dessas características não terem provocado uma perda na qualidade dos frutos ao nível de consumidor.

\section{AGRADECIMENTOS}

Os recursos desta pesquisa foram oriundos do convênio ESAM/ VALEFRUTAS/CNPq - PADFIN.

\section{LITERATURA CITADA}

BRADY, C.J.; YOUNG, R.E. Annual Review of Plant Physiology, Palo Alto, v.38, p.155-178, 1987. BRASIL, R.F.; PRAÇA, E.F.; MENEZES, J.B.; GRANGEIRO, L.C.; GOMES JÚNIOR, J.; ALVESTRE, R.E. Qualidade do melão 'Hy-Mark' em cinco estádios de maturação. Horticultura Brasileira. Brasília, v.16, n.2, p.165-166, 1998. CARVALHO, M.I.F.; CHITARRA, M.I.F.; CHITARRA, A.B.; MENEZES, J.B. Vida útil póscolheita de melão Yellow King. Revista Brasileira de Fruticultura, Cruz das Almas,. n. 3, p. 111118, 1995.

CHITARRA, M.I.F.; CHITARRA, A.B. Pós-colheita de Frutos e Hortaliças: fisiologia e manuseio. Lavras: ESAL/FAEPE, 1990. 289 p

COCOZZA, F.D.M. Aplicação pré-colheita de quelato de Cálcio e Boro em melão 'Gália': desenvolvimento e qualidade dos frutos. $1997.38 \mathrm{p}$. (Tese mestrado), ESAL, Lavras, MG

DIAS, R.C.S.; COSTA, N.D.; CERDAN, C.; SILVA, P.C.G.; QUEIROZ, M.A.; ZAZU, F.; LEITE, L.A.S.; PESSOA, P.F.A.; TERÃO, D.A. A cadeia produtiva do melão no Nordeste. In: CASTRO, S.M.V.; GOEDERT, W.J.; FREITAS FILHO, A.; VASCONCELOS, J.R.P. Cadeias produtivas $e$ sistemas naturais. Brasília, MAA/EMBRAPA, 1998, p.441-494.

FILGUEIRAS, H.A.C.; MENEZES, J.B.; ALVES, R.E.; COSTA, F.V.; PEREIRA, L.S.E.; GOMES JÚNIOR, G. Colheita e manuseio póscolheita. In: ALVES, R.E. (Org.) Melão: pós-colheita. Brasília. Embrapa Comunicação para transferência de Tecnologia, 2000. cap.3, p.23-40.

GAYET, J.P. Características das frutas de exportação. In: NETO, A.G. Melão para a exportação: procedimento colheita e pós-colheita. Brasília, MAARA/FRUPEX, 1994, p.11-21.
GONÇALVES, F.C.; MENEZES, J.B.; ALVES R.E. Armazenamento de melão 'Piel Del Sapo', sob condições ambiente. Horticultura Brasileira, Brasília, v.14, n.1, p.49-52, 1996.

GOMES JÚNIOR, J. Suscetibilidade a danos pelo frio de melóes amarelos 'AF-646'e 'Rochedo'. 2000. p.42, (Tese mestrado), ESAM, Mossoró. GOMES JÚNIOR, J.; MENEZES, J.B.; SOUZA, P.A.; GUIMARÃES, A.A.; SIMÕES, A.N. Armazenamento refrigerado de melão 'Hy Mark'. Horticultura Brasileira, Brasília, v.18, 2000. Suplemento. Revista. Trabalho apresentado no $40^{\circ}$ Congresso Brasileiro de Olericultura, 2000.

JANDEL SCIENTIFIC. User's Manual. Califórnia: Jandel Scientific, 1991. 280 p.

KRAMER, A. Fruits and Vegetables. In: KRAMER, A.; TWIGG, B.A. Quality Control for the Food Industry. Connecticut: Avi Publishing Company, 1973. v.2, p.157-227.

KROEN, W.K.; PHARR, D.M.; HUBER, S.C. Root flooding of muskmelon (Cucumis melo, L.) affects fruit concentration but not leaf carbon exchange rate. Plant Cell Physiology, v.32, n.4 p.467-473. 1991

MAYBERRY, K.S.; HARTZ, T.K. Extension of muskmelon storage life through the use of hot water treatment and polyetilene wraps. HortScience, v.27, n.4, p.24-236, 1992.

MENEZES, J.B.; CHITARRA, A.B.; CHITARRA, M.I.F.; CARVALHO, H.A. Caracterização pós-colheita do melão amarelo “Agroflora 646". Horticultura Brasileira, Brasília, v.13, n.2, p.150-153, 1995.

MENEZES, J.B. Qualidade pós-colheita de melão tipo Gália durante a maturação e o armazenamento. 1996.157 p. (Tese doutorado), UFLA, Lavras, MG.

MENEZES, J.B.; GOMES JÚNIOR, J.; ARAÚJO NETO, S.E.; SIMÕES, A.N. Armazenamento de dois genótipos de melão amarelo sob condições ambiente. Horticultura Brasileira. Brasília v.19, n.1, p.42-49, 2001.

MORAIS, P.L.D. Potencial de vida útil pós-colheita de quatro genótipos de melão tipo Gália. 1998. 34 p. (Monografia graduação), ESAM, Mossoró, RN.

NORUSIS, M.J. SPSSPC statistics. Ilinois: SPSS Inc., 1990.

SOUZA, M.C.; MENEZES, J.B.; ALVES, R.E. Tecnologia pós-colheita e produção de melão no estado do Rio Grande do Norte. Horticultura Brasileira. Brasília, v.12, n.2, p.188-190, 1994. 